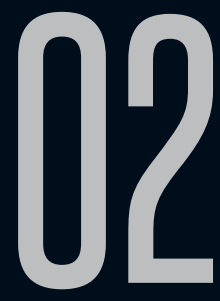

\title{
DE MONSTROS E MALDADES. LUIZ EDUARDO DA SILVA ANDRADE E JOSALBA FABIANA DOS SANTOS (ORGS). 2015.
}

Pedro Puro Sasse

Recebido em 28 ago 2016. Pedro Sasse é doutorando em Estudos de Literatura Aprovadoem 02 out 2016. pela UFF e mestre em Teoria da Literatura e Literatura Comparada pela UERJ. Atualmente desenvolve o projeto "Expressões do medo: crime, literatura e cultura no Brasil". É professor substituto da Faculdade de Formação de Professores da UERJ. Contato: pedro_sasse@hotmail.com. 
O título da obra é formado por uma antítese quase indetectável à primeira vista. Afinal, nosso impulso é, antes, ver a associação dos dois elementos como algo natural, fazendo parte de um mesmo campo semântico no qual poderíamos, ainda, incluir o termo "medo", por exemplo. Ao tentarmos, contudo, conceituá-los, surgem as diferenças que os opõem.

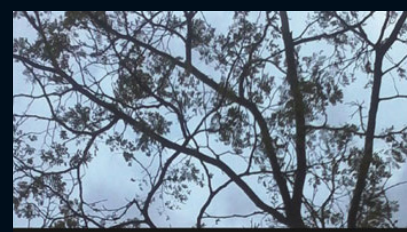

DE MONSTROS E MALDADES

Organizadores
Luiz Eduardo da Silva Andrad

Josalba Fabiana dos Santos

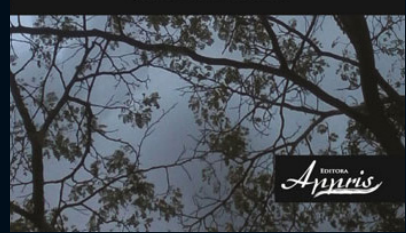

O mal (ou a insolúvel questão "o que é o mal?") parece resistir, desde a filosofia clássica a uma definição que dê conta de sua complexidade ontológica. Como Zygmunt Bauman percebe em Medo líquido, conseguimos ver apenas manifestações do Mal, enumerá-las, agrupá-las. Qualquer tentativa, contudo, de definir o Mal através dessas manifestações, transforma-o em outra coisa: em crime ou pecado, por exemplo, ambos transgressões de normas que, de forma alguma, porém, são capazes de esgotar o alcance da ideia. O Mal seria, assim, em uma definição paradoxal, algo que não se pode definir, algo cuja existência não se explica, não se compreende, não se revela como um todo, mas que é capaz de se revelar como um elemento desestabilizador do mundo ordenado que tentamos construir.

Etimologicamente, como bem ressalta Jeffrey Jerome Cohen em "A cultura dos monstros: sete teses", o Monstro se opõe à insondabilidade do Mal ao ser monstrum, aquele que revela, aquele que adverte. Presente nas mais diversas culturas desde o início da humanidade, seu poder reside justamente na capacidade de 
tornar concreto aquilo que é abstrato, de dar corpo ao etéreo, de dar forma e sentido ao desconhecido. Se não podemos enfrentar aquilo que sequer podemos definir, construímos monstros que nos permitam, em uma encenação, confrontar o Mal, e até mesmo vencê-lo - ainda que momentaneamente.

Dessa forma, o Mal e o Monstro são opostos que se complementam dialeticamente. Sempre que um monstro perde sua capacidade de representar os aspectos ininteligíveis - e, assim, aterrorizantes - da sociedade que o criou, sua função se encerra e ele é destruído, ressurgindo de suas próprias cinzas com uma nova e igualmente assustadora forma.

De monstros e maldades pode, contudo, surpreender por um fato que, a princípio, é um contrassenso: não há monstros nele. Não se tentarmos identificá-los fazendo uso da ideia de monstro difundida no senso comum. Se pedirmos para uma criança desenhar ou descrever um monstro, o produto não será muito diferente daquele que produziríamos nós mesmos. Deve-se a isso o fato de que o senso comum consolidou em nós, como sinônimo de monstro, a morfologia do horror sobrenatural (sobretudo inglesa e estadunidense) em que predominam vampiros, fantasmas e bestas repugnantes.

Eis um grande mérito deste livro. Seus dez artigos investem não naquilo que nossa intuição já seria capaz de dizer, mas exploram monstruosidades que, quase contrariando sua etimologia, se escondem na literatura: personificações do crime, da depressão, da miséria, da incerteza, da avareza. Opondo-se, ainda, a teratologia do horror sobrenatural, as monstruosidades, aqui, não são revestidas 
de uma morfologia fantástica, mas assustam justamente por ter, como elemento central, o próprio ser humano.

No artigo "O duplo e a nossa condição", temos uma boa exemplificação dessa proposta. César de Oliveira Santos, ao analisar o conto "Teleco, o coelhinho", de Murilo Rubião, mostra como a criatura fantástica que fala e se metamorfoseia em qualquer animal, só consegue causar aversão no narrador-protagonista ao tentar, justamente, tornar-se humano. Para Santos, "não é o sobrenatural que apavora e é temível, como é comum nas narrativas fantásticas dos séculos XVII, XVIII e XIX, mas sim a realidade humana" (p.118119). Teleco, como um duplo - ainda que incompleto - do homem, desautomatizaria a ideia que temos de nós mesmos, revelando os males inerentes à própria condição humana: a solidão, o desamparo e, enfim, a própria morte.

Único artigo em que há a presença de um elemento fantástico em todo o livro é sintomático perceber como, mesmo nele, vemos um direcionamento não para o temor daquilo que nos é alheio, mas para o choque causado pelo estranhamente comum. Ofuscada pelo cotidiano, nossa percepção sobre os monstros criados na própria experiência humana, seja existencial ou social, é aguçada pelas leituras que aqui se apresentam, devolvendo ao monstro o caráter de monstrum que lhe foi arrebatado.

A morte, elemento fundamental para um estudo de monstros e maldades, é tema central de dois artigos do livro. Seguindo, contudo, a positiva quebra de expectativas da obra, tal elemento não é abordado através de sua forma mais tradicional, àquela em que se teme a morte em si, mas através da perspectiva do suicida, que, em última instância, é justamente quem decide enfrentá-la. 
Danielle Santos Rodrigues, em "O suicídio no conto brasileiro contemporâneo: sacrifício e ritual", mostrará como, surpreendentemente, o próprio suicida - que em tese só ameaçaria a si mesmo - pode representar um monstro para a sociedade. Nos dois contos analisados pela autora, "A ponte o horizonte", de Marcelino Freire, e "Um discurso sobre o método", de Sérgio Sant'Anna, o suicídio não é considerado um ato plenamente voluntário, mas o resultado de o suicida ter sua vontade aniquilada pelas massas, sendo assim compelido a se matar. Nesse sentido, a construção dos monstros torna-se peculiar: a sociedade condensa seus males na figura do suicida, que é visto como "aquele que chama atenção e causa repulsa, é o 'estrangeiro', o diferente e indiferente perante o corpo social" (p.55). Aos olhos do outro, a morte do monstro restaurará a ordem.

A situação pode, contudo, ser vista por outro ângulo. O autor atenta para como, se observarmos a perspectiva da personagem suicida dos contos, "sujeito trabalhador, explorado e inseguro em relação ao futuro (...), invisível" (p.60), veremos que ele é vítima de uma sociedade cujo desejo de violência e sangue é aplacado apenas com a morte de seus párias. Nessa ótica, a própria cidade pode tornar-se um monstro: indiretamente assassina, ao incentivar a suposta tentativa de suicídio de "Um discurso sobre o método", e diretamente assassina, ao empurrar o desistente suicida em "A ponte o horizonte".

Se, no artigo de Rodrigues, o suicídio ritualístico concentra no próprio suicida o mal a ser eliminado, no artigo de Eline Marques dos Santos, "Os horrores de Buell Quain em Nove noites, de Bernardo Carvalho", a abordagem é oposta. O suicídio misterioso 
do antropólogo americano Buell Quain é, segundo a autora, uma tentativa de fuga dos verdadeiros horrores experimentados em vida pela personagem. Motivada pela investigação da morte de Quain, a história aponta para o passado, tentando entender que causas haveriam levado ao suicídio do antropólogo.

Santos salienta como Quain era atormentado por "fantasmas e lembranças catastróficas" (p.174) desse passado, que, conforme vão sendo recuperados pelos depoimentos sobre sua morte, reconstroem o monstro do qual ele fugia. A relação familiar aparece, assim, como elemento basilar de seu horror: a mãe dominadora, o pai alcoólatra e a possível relação incestuosa com a irmã. Sua fuga desse mundo, buscando nas tribos indígenas o lar que não pudera ter, contudo, só intensifica o problema: a alteridade de "seus hábitos, costumes e comidas são repugnantes para o antropólogo" (p.178). Sem poder estabelecer-se, de fato, em um lugar e assim consolidar uma identidade, Quain seria uma personagem marcada pela incerteza e pela descrença das instituições familiares e sociais, em um mundo ao mesmo tempo globalizado e desagregado. Com isso, Nove noites torna-se, para a autora, um representante dos temores pós-modernos através de um sentimento de nãopertencimento que torna qualquer lugar sempre um lugar do outro, um lugar monstruoso.

As questões envolvendo passado, lar e identidade são centrais também na obra de Clarice Lispector. Normalmente abordada através de outras perspectivas, dois artigos do livro se propõem a analisar a obra clariceana pela perspectiva da figura do monstro. Para tal, exploram dois espaços narrativos quase opostos: Amael Oliveira, em "Um monstro doméstico em Clarice Lispector", volta- 
se para o ambiente doméstico burguês, em que os monstros emergem de uma magnificação de elementos próprios do cotidiano. Já Thiago Maciel Guimarães, em "O prisma e a voz: considerações sobre a monstruosidade metafórica em A hora da estrela", optará pelo espaço urbano, periférico, em que a alteridade radical de Macabéa será responsável por transformá-la em monstro aos olhos da sociedade hegemônica.

Estratégia recorrente para se criar monstruosidades, a magnificação é o processo pelo qual um elemento natural é ampliado até atingir um tamanho fora do comum. Enquanto o cinema e a literatura de horror são pródigos na criação, através desse método, de animais gigantescos ou criaturas com membros corporais desproporcionais, Oliveira mostrará como, em Clarice, essa magnificação é aplicada aos elementos mínimos do dia-adia das personagens, e esse "exagero das formas acaba por gerar figuras monstruosas" (p.75).

Entre as figuras magnificadas pela descrição dos narradores clariceanos, destaca-se a figura da barata. Inofensiva (ainda que repugnante) na vida real, Oliveira mostra a recorrência de sua representação monstruosa na obra de Clarice, seja como metáfora - da velhice, do asco, do primitivo, do amoral, do inumano etc. ou como inseto propriamente dito. Tomando a barata como inseto, seria possível identificar, ao longo de $A$ paixão segundo G.H., diversas características que colaboram para a transformação da barata em monstro: sua descrição repugnante, a atração e a repulsa concomitantes que inspira na protagonista, sua aproximação com criaturas mitológicas terríveis, entre outras. 
A força do texto clariceano residiria na capacidade de apresentar não o extraordinário como monstruoso, mas, pelo contrário, em mostrar como um jogo de perspectiva é capaz de produzir monstros tão eficazes quanto as antológicas criaturas do horror. Infiltradas na rotina de qualquer cidadão, tais elementos contêm em si a capacidade monstruosa de tirar o mundo dos eixos (ainda que seja o mundo doméstico), de solapar a estabilidade, de abalar, enfim, a sensação de segurança que o lar deveria transmitir.

O mesmo abalo da ordem causado no interior da casa pelas monstruosidades de $A$ paixão segundo G.H. será observado por Thiago Guimarães no exterior urbano de $A$ hora da estrela. Seguindo a mesma ideia de relativização do monstro observada por Oliveira, em que sua construção poderia depender unicamente de um jogo de perspectiva, Guimarães defende a ideia de que Macabéa seria, ao mesmo tempo, monstro e vítima, representante do mal e espelho que aponta para a verdadeira maldade imposta sobre ela.

Por um lado, vemos a construção de uma personagem cujas características a aproximariam de um monstro: a aparência grotesca, a repugnância causada por seus hábitos pouco higiênicos e o fato de habitar uma zona periférica, por exemplo. Oposto, no entanto, ao que tradicionalmente vemos no horror, essa monstruosidade está dissociada da maldade que deveria encarnar. Apesar da aparência de algoz, Macabéa, na verdade, seria vítima de sua própria condição. Como no conceito de bode expiatório trabalhado anteriormente por Danielle Rodrigues, a própria sociedade, em um ritual perverso, cria o monstro ao projetar nele os males que deseja expurgar de si apenas para depois exigir seu extermínio. Macabéa, nesse sentido, é uma ameaça não por sua condição em si, mas 
por expor através de sua condição a arbitrariedade, a injustiça e o mal cometido não por ela, mas contra ela. Em última instância, Macabéa é um monstro aos olhos da elite apenas por refletir a face dos verdadeiros monstros, ou seja, eles mesmos.

O sertão de onde parte Macabéa para chegar ao Rio é, também, ambiente de diversas outras figurações dessa dicotomia monstro/ vítima social. Se a protagonista clariceana já põe em cheque as tradicionais ideias de monstro, ainda mais complexa é a figura de Lampião, analisada por Ozeias Pereira da Conceição Filho, no artigo "Lampião revisitado: monstro e duplo na Literatura, no Cinema e no Jornalismo".

Diferentemente do que ocorre com Macabéa, cujos atos e pensamentos em nada colaboram para a monstruosidade que the é atribuída, o mais famoso cangaceiro da história era amplamente conhecido pela crueldade de seus atos. Conceição Filho observa, em seu artigo, como a representação de Virgulino oscila entre ser ele "a própria encarnação do mal" (p.132) ou "um tipo de herói, um guardião que luta pelos pobres" (p.135). Se, em A hora da estrela, o problema é ontológico, um descompasso entre a figura monstruosa e a origem dos males, na literatura que tematiza o cangaço (e, mais genericamente, o banditismo em si), o que está em jogo é uma questão moral: os atos de Lampião tornam-no um monstro ou sua situação social o redimiria por seus atos?

O autor vai além e amplia o problema ao mencionar a brutalidade do Estado ao capturar Virgulino. Ao ser decapitado e ter a cabeça exposta "em um freak show em nível nacional" (p.139), a morte do bandido magnifica o caráter sanguinário da sociedade que aparece 
como pano de fundo de diversos outros artigos do livro. Se Lampião é violento, igualmente o é "a sociedade, que se utilizou dos mesmos (ou piores) atos horrendos" (p.139) para executá-lo. Sem saídas fáceis, o artigo de Conceição Filho nos ajuda a perceber os perigos que uma análise que leva em conta apenas uma perspectiva pode ter nesses casos. Ao lançar mão da Literatura, do Cinema e do Jornalismo, observando os diferentes posicionamentos e interesses por trás da construção social do monstro, o autor ajuda-nos a perceber as sutilezas por trás de sua problemática representação.

O embate entre a relativização do mal e a presença de um mal absoluto são abordados com riqueza de detalhes no artigo "Riobaldo em perspectiva: o homem, o diabo e o mal", de Francisco Gomes de Andrade. O diabo, uma das mais frequentes manifestações do mal absoluto na cultura ocidental, é uma figura recorrente na literatura sertaneja. Guimarães Rosa, conhecedor de tal tradição, apropriase dessa figura em Grande sertão: veredas. Contudo, subverte seus sentidos. A dúvida sobre a existência do diabo, sustentada ao longo do romance por Riobaldo, abriria espaço para uma reflexão sobre as próprias origens do mal: de um lado metafísica e incontrolável, representada pelo próprio Satã e, de outro, pela barbárie primitiva própria do ser humano.

Para Francisco Gomes de Andrade, Riobaldo, por fim, nega a existência do demônio enquanto "entidade sobrenatural e trascendente, que paira sobre o mundo cometendo mil estripulias e desgraças" (p.47), optando por uma visão da "natureza demoníaca como símbolo do mal interiorizada no sujeito" (p.48). Dessa forma, a personagem insere-se na concepção nietzschiana de "espírito livre", em que, liberta dos paradigmas morais ocidentais cristãos, ela pode 
subverter as noções engessadas de Bem e Mal, de Deus e Demônio, de pecado e culpa etc. Ao passo que algumas das análises do livro abordam o monstro como uma construção social, abordagens como a deste artigo oferecem uma perspectiva mais internalizada do Mal: em certa medida, independente das construções sociais, seríamos todos monstros de nós mesmos.

Em total consonância com esse processo de internalização do demônio e de subversão dos valores morais engessados, Cristiano de Jesus Rosa, em "Do fantasma ao morto-vivo: uma leitura sobre 'o mundo sem deus'", observará o universo caracterizado pelo crime, violência, danação, transgressão, loucura, vícios e desespero criado na trilogia obscura de Lúcio Cardoso, composta pelos romances Inácio, $O$ enfeitiçado e Baltazar.

Focando-se na personagem de Inácio Palma, protagonista do segundo livro da série, mas central, também, para os outros dois, Jesus Rosa fará uma análise comparativa com Drácula, de Bram Stoker. O autor propõe que Inácio seria, como Drácula, uma espécie de morto-vivo, ainda que metafórico. Dessa forma, sua presença é sempre fantasmagórica, amedrontadora e fugidia: seja ao "voltar dos mortos", na busca por um filho que abandonara há anos; seja em sua aparente ausência de vida; ou em sua capacidade de sobreviver à morte nos pesadelos de suas vítimas. No entanto, mesmo havendo muitos paralelos entre Inácio e Drácula, surge novamente a diferença que parece marcar os monstros que vemos ao longo dos artigos do livro: Jesus Rosa diferencia o personagem de Cardoso do vampiro de Stoker em relação à autoconsciência do mal e ao remorso, uma vez que "Inácio aparenta se redimir de seus delitos, enquanto Drácula se mantém implacável diante de suas 
maldades" (p.158). Assim, enquanto Drácula representaria um Mal absoluto, cujos atos não são passíveis de questionamento moral, Inácio, enquanto ser humano, seria ao mesmo tempo monstro, por conta de seus atos, e vítima, por todos os danos que causa a si mesmo em sua jornada.

O espaço obscuro, marcado pelo pecado, pelo vício e pela violência que vemos em Lúcio Cardoso, é, também, basilar na obra de Cornélio Pena. Luiz Eduardo da Silva Andrade, em seu artigo "Elipses do medo em A menina morta, de Cornélio Penna", parte da metáfora da elipse, figura típica da arte barroca, para mostrar como o medo, nessa obra, é marcado por um jogo de claro-escuro, no qual os mistérios e monstruosidades, que ora se ocultam, ora se deixam ver, servem para movimentar uma trama circular e claustrofóbica.

Segundo o autor, A menina morta, que já começa com os preparativos para o enterro de uma criança, constrói um ambiente angustiante em que as personagens se encontram confinadas e deslocadas do tempo, em uma circularidade sem escapatória, "perdidas em um labirinto que tem como saída apenas o caminho da maldade, da violência, da culpa, e da espera da morte" (p.211). Nele, o mal pode ser encontrado tanto em uma dimensão naturalmetafísica, de cunho mais subjetivo (em que o medo da morte e do desconhecido se destacam) quanto em uma dimensão éticosocial (em que o medo do outro, a escravidão, a violência e o patriarcalismo entram em jogo), vinculando as monstruosidades representadas na obra a um momento sociocultural específico. A abrangente análise de Silva Andrade abre espaço, assim, para unirmos esses dois polos representativos do mal - seja ele 
condensado na figura individual ou na coletividade, seja ele um tormento interior ou um construto social.

Já Otávio Monteiro Pereira, em "Avareza e embrutecimento em Eugénie Grandet", retoma um tema caro à maioria dos artigos do livro: o Mal como um elemento inerente ao homem. Ainda que trate de um dos pecados capitais, a fundamentação teórica de Pereira, partindo de Agostinho e Kant, mostra como o mal "só pode ser engendrado a partir da ação livre do indivíduo" (p.190). Em seu trabalho, Pereira, ao analisar o romance de Balzac, observará como a avareza, grande mal do pai de Eugénie, afeta a vida de sua família, criando um ambiente de opressão, miséria e medo. Nessa análise, ganha destaque a forma como o capitalismo exacerbado sobrepõe-se aos valores humanos, embrutecendo as personagens avarentas e arrastando aqueles que estão à sua volta - perpetuando, assim, o mal.

Ao longo dos dez artigos do livro, o leitor poderá ler nos monstros características das sociedades que os engendram, sobretudo as monstruosidades escondidas nas práticas culturais que o próprio cotidiano mascara. Dessa forma, De monstros $e$ maldades avança mais um passo nesse caminho, ainda incipiente no Brasil, de mostrar que o medo é, também, um elemento central para entender nossa sociedade. Além do valor das análises em si, os artigos abrem diversas portas de estudo nesse campo que precisa sempre ser revisitado, uma vez que, como Jeffrey Cohen bem observa, o monstro sempre escapa e renasce, sobre outra forma. 